\title{
Drug Factors Influencing Its Use Among Undergraduate Students of A Tertiary Institution In Nigeria
}

\author{
Aremu Saad Bolakale \\ Federal Medical Centre, Gusau \\ Shehu Adamu \\ Department of Community Medicine, Ahmadu Bello University, Zaria \\ Boman Yusuf Markus \\ Federal Neuro psychiatric Hospital, Kaduna
}

\begin{abstract}
OBJECTIVE: Drug use and abuse have been reported to be one of the main causes of impairment of social competence and performance among students. Also, school drop out, criminal tendencies and poor social interaction have also been reported to be associated with drug abuse among these students. Knowing the Prevalence and patterns of drug use, number of drug use, reason for use, sustainability and duration of drug used as drug factors will help in primary prevention strategy in tertiary institutions in Nigeria and globally. METHODS: A descriptive cross sectional study involving four hundred and forty (440) subjects selected through multistage sampling techniques. All the subjects consented and participated in the study. Self administered socio demographic, WHO students' drug use and drug factors influencing use questionnaires were administered to the subjects to fill through their class representative. Statistical package for social science (SPSS) 15th editions was used in Data analysis. RESULTS: Four hundred and forty (440) students drawn from 3 faculties of the university participated in the study. One hundred and fifty (150) respondents constituting $34.1 \%$ were from faculty of Engineering, one hundred and fifteen (115) respondents constituting $\mathbf{2 6 . 1 \%}$ were from faculty of Education while one hundred and seventy five (175) respondents constituting about $39.8 \%$ were from college of Medicine. One hundred and thirteen subjects (25.7\%) used one and more of all the 10 drugs examined by the questionnaires. Duration of tobacco use revealed that 40 had used it 5years and above, 15 used it between 3-5years, 4 used it between 6months1year while 2 tobacco users had 1-3years as duration of usage. The differences was statistically significance $(\mathrm{df}=4, \mathrm{x} 2=12.07, \mathrm{p}=0.01)$. All the 6 cocaine users $(1.4 \%)$ take 3 other drugs alongside cocaine. The difference was also statistically significant $(\mathrm{df}=\mathbf{3}$, $\mathrm{x} 2=26.21, \mathrm{p}=0.00$ ). Multiple drug use of 3 and more was found to be significant with many of the drugs examined. CONCLUSIONS: Prevalence, patterns and drug factors revealed that psychoactive drug use was found among students of Ahmadu Bello University Zaria like in other institutions of higher learning in Nigeria. Appropriate interventions like health education, social support system, counseling, referral systems, parental supervision and enforcement of necessary laws by regulatory agencies were some of the recommendations to curb the menace in our institutions in Nigeria.
\end{abstract}

Key Words : Psychoactive drug use and Abuse, Drug Factors Influencing Use, Undergraduate Students in Nigeria. 


\section{INTRODUCTION}

World Health Organization expert committee on drug dependence defined drug as a natural or synthetic substance which when taken into a living body affect its functioning or structures ${ }^{1 .}$

Over the years, the definition of drug abuse has varied among researchers although operational definitions are now in place. Drug abuse is defined as the use of illegal drugs, or the misuse of prescription or over the counter drugs. Another defines drug abuse as the improper, excessive, irresponsible or self damaging use of addictive substances. The two internationally recognized definitions, which are similar in most aspects are the diagnostic and Statistical Manual of Mental Disorder (DSM IV 1994) ${ }^{2}$ and the International Classification of Diseases tenth edition(ICD 1992) 3 .

Psychoactive drug abuse is therefore defined as a maladapted pattern of substance use leading to clinically significant impairment or distress as manifested by one or more of the following occurring within a 12 months period.

a. Recurrent substance use resulting in a failure of fulfilling major role obligation at work, school or home (e.g repeated diseases or poor work performance related to substance use).

b. Recurrent substance use in situation in which it is physically hazardous e.g drug and automobile or operating a machine when impaired by substance use.

c. Recurrent substance related legal problems

d. Recurrent use despite recurrent social or interpersonal problems caused or exacerbated by effects of substance use.

Reasons for use of drugs especially among youths include, curiosity, to feel good, to reduce stress and to feel grown up among others. Some will experiment and stop, others will turn into occasion users while other will develop addiction moving into more harmful drugs thereby causing harm to themselves and others. ${ }^{(4)}$

The 2001 world drug report of the United Nations Drug Control Office estimated that the extent of drug abuse in the world, involved about 180 million people, which represents 3\% of the global population. The majority of drug users used cannabis $80 \%$, followed by amphetamine $16 \%$, cocaine $8 \%$, heroine $5 \%$ and opiate $2 \%$. Report of drug use among students in the USA revealed that more than half of the students tried an illegal drug before they graduated from high school. About $65 \%$ tried cigarettes by $\left(12^{\text {th }}\right)$ twelve grade, $25 \%$ of eight grade and $62 \%$ of twelve grade have been reported to have been drunk at least once ${ }^{5}$.

In England and Wales, self-report surveys indicated that about one third of those aged 1659 years have tried drugs in their lifetime. However, the proportion using drugs in the last year was $12 \%$ and in the last one month was $8 \%$. Psychoactive substance alcohol, tobacco and khat have been available for traditional use in Africa for many years. The use of alcohol during ceremonies and to facilitates social interaction has also been reported since ancient times ${ }^{6}$. In a study by Onya and Flisher, amongst rural high school students in Mankweng, Limpopo Province, South Africa, the prevalence rates for previous month (recent) use of alcohol, cigarettes, cannabis, glue and spirits were $6.4 \%, 10.5 \%, 1.4 \%, 1.2 \%$ and $0.8 \%$ respectively was reported.7. A study of drug abuse among students of Ambrose Alli University Ekpoma Nigeria by okoza \& Aluede (2009), 414 university students drawn from four faculties participated in the study. Modified student's drug use questionnaire was used. The result revealed $66 \%$ abuse alcohol, 25\% abuse kolanut 20\% abuse tobacco,20\% Marijuana, 21.3\% Librium, 32.9\% Valium, 17\% Amphetamine , 7\% Reactivan, 31.2\% mandrax, 28. 7\% Chinese capsule and $16.2 \%$ Cocaine.The study revealed widespread use of cannabis, amphetamine, cocaine and 
other licit drugs. ${ }^{8} \quad$ Oshikoya and Alli in their studies on perception of drug abuse amongst Nigerian undergraduates also identified dependence and addiction as one of the major consequence of drug abuse, characterized by compulsive drug craving seeking behaviours even in the face of negative consequences. ${ }^{9}$ Adeyemo et al in a study of Prevalence of Drug Abuse Amongst University Students in Benin City, Nigeria revealed that $46.6 \%$ of the sample respondents have taken drugs for non-medical purposes at least once. Coffee and alcohol were the most commonly abused drugs and majority of the respondents agreed that students take drugs as a result of poor teacher-student relationship, improper parental upbringing, as well as the influence of peer pressure. ${ }^{10}$ Drug use and abuse have been reported to be one of the main causes of impairment of social competence and performance. School drop out, criminal tendencies and poor social interaction have also been reported to be associated with drug abuse. Knowing the Prevalence and patterns of drug use, number of drug use, reason for use, sustainability and duration of drug used as drug factors will help in primary prevention strategy in tertiary institutions globally.

Study Population : Students of Ahmadu Bello University.

Inclusion criteria:- Undergraduate students(Samaru campus) of Ahmadu Bello University, Zaria

Exclusion criteria:- Diploma, Postgraduate students of the school as well as students of congo campus of the institution.

\section{Study design}

The study design was descriptive cross sectional study. Registered students of Samaru campus of the institution were used for the study.

\section{Sampling size calculation}

The formula use for calculation is

$$
N=\frac{Z^{2} p q}{d^{2}} \quad(q=1-p)
$$

\section{Minimum Size}

Where:

$\mathrm{Z}=\mathrm{A}$ constant at $95 \%$ confidence internal interval from The table for two tail study value is $1.96 \%$.

$\mathrm{P}=$ Prevalence of substance use among university students is $52 \%(\mathrm{P}$ is $=0.52$ ) (Yunusa obembe \& Asogwa (2012) $)^{11}$

$\mathrm{q}=0.48$

$d=0.05$ degree of accuracy desired, that is precision error that will be tolerated in the study is 0.05 .

$$
\mathrm{N}=\frac{1.96^{2} \times 052 \times 0.48}{0.05^{2}}=383.5
$$

Attrition Ratio $=316 / 2200 \times 100=14 \%$

$14 / 100 \times 384=53.76$

Approximation $=384+54=438$

\section{Sampling Technique}

Multistage and random sampling technique was used to select the minimum sampling size.

Stage one : Faculty( Medicine, Engineering and and Education) 
Stage Two : Deptarment( Medicine, Electrical and Physical education)

Stage Three : Levels( 100- 600 levels)

Stage Four : Respondents

Total Minimum sample size $=\mathbf{4 3 8}$

\section{Study instrument}

The world health organization (WHO,1980) ${ }^{12}$ modified self administered questionnaire for student drug use survey was adopted for the study. The questionnaire had previously been reported to have acceptable reliability and validity in this environment. The questions consist of socio-demographic characteristic questions and use of specific substance questions and factors contributing to drug use.

\section{Procedure}

The self administered questionnaires were distributed for filling through the class's coordinator to randomly selected participants in September/October 2012; the returned questionnaires were thereafter analyzed. All the levels of study except 600level of college of medicine that were not available as of time of data collection participated in the study.

\section{DATA ANALYSIS}

Data analysis was done by statistical package for social science (SPSS) 15th editions. Description statistic for examples mean and S.D were calculated. Chi-square was used for categorical variables and level of significance was set at $\mathrm{P}<0.05$.

\section{ETHICAL CONSIDERATION}

The ethical committee of Ahmadu Bello University Zaria Kaduna State was informed about the study and its purpose. Permission was obtained from the Department of Community Medicine before the study was conducted.

The students that participated in the study were also informed and consent obtained before commencement of the study. The participants were informed that they can decline participation at any stage of the study. Privacy and confidentiality were also assured before data taken.

\section{RESULT}

Four hundred and forty (440) students drawn from 3 faculties of the university participated in the study. These faculties were Engineering, Education and College of Medicine (Table1).

TABLE 1

\begin{tabular}{|l|l|l|}
\hline FACULTY & Frequency & \%(percent) \\
\hline Engineering & 150 & 34.1 \\
\hline Education & 115 & 26.1 \\
\hline Medicine & 175 & 39.8 \\
\hline & $\mathbf{4 4 0}$ & $\mathbf{1 0 0}$ \\
\hline
\end{tabular}

One hundred and thirteen subjects had used one or more substance in their lifetime. Three hundred and twenty seven participants revealed they had never taken any substance in their lifetime. The prevalence of substance use among the students was therefore, twenty five point seven percent $(25.7 \%)$.

Table 2 : revealed the types of substances used by the respondents. Alcohol was most prevalently used. Seventy four constituting $16.0 \%$ use alcohol while tobacco was the next 
prevalently used substance constituting about $13.9 \%$. Cannabis was the third commonly substance used. About 32 participants (7.3\%) used cannabis. Eleven participants (4.8\%) used sedatives/tranquillizer. Sniff use participants were $3.9 \%$, stimulant $3.6 \%$, Opoid $2.7 \%$, Heroine $1.6 \%$, and Cocaine $1.4 \%$. The least drug used among the participants was hallucinogen $(0.9 \%)$.

TABLE 2 : Types of drug Use and their prevalence.

\begin{tabular}{|l|l|l|}
\multicolumn{1}{c}{ Drugs } & Freq & Perc \\
\hline Tobacco & 61 & $13.9 \%$ \\
\hline Cannabis & 32 & $7.3 \%$ \\
\hline Alcohol & 74 & $16.8 \%$ \\
\hline Tranquillizer/Sedatives & 21 & $4.8 \%$ \\
\hline Cocaine & 6 & $1.4 \%$ \\
\hline Stimulant & 16 & $3.6 \%$ \\
\hline Hallucinogen & 4 & $0.9 \%$ \\
\hline Heroine & 7 & $1.6 \%$ \\
\hline Opoid & 12 & $2.7 \%$ \\
\hline Sniffs & 17 & $3.9 \%$ \\
\hline
\end{tabular}

\section{Tobacco}

\section{DRUG FACTORS}

61 students of 440 used tobacco and the prevalence of tobacco use was $13.9 \%$. 29(56.9\%) were introduced to use of tobacco by friends, $14(56 \%)$ by relatives and $18(50 \%)$ by other people. On reason for use of it, $19(50 \%)$ used it to remained alert, $10(52.6 \%)$ to stimulate selves, $9(50.9 \%)$ to read, $6(60 \%)$ to satisfy friends while $17(58.6 \%)$ used it for boldness to talk. $20(54.1 \%)$ sustained tobacco use through their friends, $2(33.3 \%)$ through their relations and $38(55 \%)$ through their pocket money. Duration of tobacco use revealed that $40(64.5 \%)$ had used it 5years and above, 15(53.6\%) used it between 3-5years,4(44.4\%) used it between 6 months-1year while $2(15.4 \%)$ tobacco users had 1-3years as duration of usage. The differences was statistically significance $(\mathrm{df}=4, \mathrm{x} 2=12.07, \mathrm{p}=0.01)$. Number of drugs usage alongside with tobacco revealed $19(86.4 \%)$ used tobacco with 3 other drugs, $9(81.8 \%)$ used tobacco and 2 other drugs, 15(75\%) used tobacco and one other drug while $18(30 \%)$ used only tobacco. The difference was also significant $(\mathrm{df}=3, \mathrm{x} 2=30.15, \mathrm{p}=0.00)$.

\section{Cannabis}

32 out of 440 respondent used cannabis, therefore the prevalence was $7.3 \%$.

19(37.3\%) were introduced to cannabis usage by their friends, 7(28\%) by their relatives and $6(16.7 \%)$ were introduced by other people. Reasons for use include to be alert by $7(18.4 \%)$ respondents, $4(21.1 \%)$ to stimulate themselves, $4(23.5 \%)$ to read, $2(20 \%)$ to satisfy friends while $15(52 \%)$ for boldness to talk. The difference was statistically significant ( $\mathrm{df}=4$, $\mathrm{x} 2=10.69, \mathrm{p}=0.03) .15(21.7 \%)$ sustained cannabis intake through their pocket money, $14(37.8 \%)$ through friends and $3(35.5 \%)$ through relations. $19(30.6 \%)$ had duration of usage as 5years and more, $10(35.7 \%)$ between 3-5years while 2(22.2\%) between 6months and 1year while $1(77 \%)$ respondent had used cannabis between 1-3years. None had used cannabis before 6 months of the study. The difference was not significant. 18(81.8\%) used cannabis and 3 other drugs while $8(72.7 \%)$ used cannabis and 2 other drugs. $4(20 \%)$ used cannabis and one other drug whereas $2(33.3 \%)$ used only cannabis as substance use. The difference was statistically significant $(\mathrm{df}=3, \mathrm{x} 2=60.84, \mathrm{p}=0.00)$. 


\section{Alcohol}

740 f 440 respondent used alcohol, hence prevalence of $16.8 \% .35$ ( 68.8\%) were introduced by their friends, $18(75 \%)$ by their relatives, $20(55.6 \%)$ by other people while one revealed he was introduced by his parent. 20(69\%) further revealed that boldness to talk was their reason for use of alcohol, $24(63.2 \%)$ to make them alert, $11(64.7 \%)$ to read, $13(68.4 \%)$ to stimulate themselves while $6(60 \%)$ to satisfy their friends. On sustainability of alcohol intake, $45(65.2 \%)$ used their pocket money,26(70.3\%) through their friends and 3(50\%) through their parents. $36(58.1 \%)$ had taken alcohol for more than 5years, 20(71.4\%) used alcohol between 3-5years, $10(77 \%)$ between $1-3 y e a r s$ while one started its use less than 6 months. $36(60 \%)$ used alcohol as a single drug, 13(65\%) took alcohol with one other drug, 8(72.7\%) takes alcohol with 2 other drugs while 17(77.3\%) used alcohol and 3 other drugs. The differences noted were not significant.

\section{Tranquilizers/ sedatives}

21 of 440 respondents were users of tranquilizers/sedatives hence the prevalence of $4.8 \%$. $10(20 \%)$ were introduced by their friends, $5(20 \%)$ by their relatives while $6(16.7 \%)$ were introduced by other people. 10(35\%) used sedative in order to be bold, 4(24\%) used it to read, $3(16 \%)$ to stimulate themselves while $2(5.3 \%)$ to be alert. $12(32.4 \%)$ were sustained by their friends,8(11.6\%) through their pocket money while $1(16.7 \%)$ through their parents. $13(21 \%)$ had 5years and above as duration of their usage, 7(25\%) used sedatives between 3-5years while $1(11.1 \%)$ between 6months -1year. 14(63.6\%) takes sedatives and 4 other drugs, $4(63.4 \%)$ takes sedatives and 3 other drugs, 1(5\%) takes sedatives and one other drug while $2(3.3 \%)$ takes only sedatives as substance of use. The differences in number of drugs used was statistically significant $(\mathrm{df}=3, \mathrm{x} 2=48.47, \mathrm{p}=0.00)$.

\section{Cocaine}

6 of 440 respondents used cocaine hence, the prevalence was $1.4 \% .4(7.8 \%)$ of the 6 users were introduced into it use by their friends, $1(4 \%)$ by relation and one $(2.8 \%)$ by other people. $2(6.9 \%)$ used cocaine for boldness to talk and other $2(10.5 \%)$ to stimulate themselves, $1(5.9 \%)$ to read and the other one $(2.6 \%)$ to be alert. $4(10.8 \%)$ were sustained through their friends while $2(2.9 \%)$ through their pocket money. $5(8.1 \%)$ had 5years and more as their duration of intake while one(11.1\%) had used it between 6months-1year. All the 6(27.3\%) users take 3 other drugs alongside cocaine. The difference was statistically significant $(\mathrm{df}=3$, $\mathrm{x} 2=26.21, \mathrm{p}=0.00$ ).

\section{Stimulant}

16 out of 440 respondents used stimulant, therefore prevalence of stimulant use was 3.6\%. $12(23.5 \%)$ were introduced into its use by friends, $2(8 \%)$ by relatives and $2(5.6 \%)$ by other people. Reasons for use revealed that $5(13.2 \%)$ used it to be alert, $5(17.2 \%)$ for boldness to talk, $3(15.8 \%)$ to stimulate themselves, $2(11.8 \%)$ to read and $1(10 \%)$ to satisfy friends. $8(12.9 \%)$ had duration of stimulant use to be 5years and above, $5(17.9 \%)$ used stimulant between 3-5years, 2(15.4\%) between 1-3years and 1(11.1\%) used it between 6months- 1year. $11(50 \%)$ of the 16 users takes stimulant with 3 and more other drugs, 3(15\%) used stimulant and one other drug, $1(1.7 \%)$ takes only stimulant and other $1(9.1 \%)$ takes stimulants and 2 other drugs. The difference was significant. $(\mathrm{df}=3, \mathrm{x} 2=31.99, \mathrm{p}=0.00)$.

\section{Hallucinogen}

4 out of 440 respondents used hallucinogen. The prevalence was $0.9 \%$.

$3(5.9 \%)$ were introduced into its use by friends while $1(4 \%)$ by relatives. $3(15.4 \%)$ used it to stimulate themselves while $1(10 \%)$ used it to satisfy friends. $3(8.1 \%)$ sustained the use 
through their friends while one(1.5\%) used his pocket money. All(6.5\%) the users had 5years and above as the duration of hallucinogen intake. Likewise all the $4(18.2 \%)$ users used multiple drugs of 4 and more psychoactive substances. The difference was statistically significant. $(\mathrm{df}=3, \mathrm{x} 2=17.35, \mathrm{p}=0.001)$

\section{Heroine}

7 out of 440 respondents used heroine hence the prevalence of $1.6 \%$. 5(9.8\%) of the 7 were introduced by friends, $1(4.2 \%)$ introduced by relative and $1(2.8 \%)$ by other people. $3(10.3 \%)$ used it for boldness to talk, $2(11.8 \%)$ to read, $1(5.3 \%)$ to stimulate self and $1(10 \%)$ to satisfy friends. The difference was not significant. 5(13.5\%) sustained its use through friends, $2(2.9 \%)$ used their pocket money. 1(7.7\%) had used heroine between 1-3years while $6(9.7 \%)$ had 5years and above as duration of their usage. 6(27.3\%) takes heroine with 3 and more drugs while one $(1.7 \%)$ only takes heroine. The difference was significant ( $d f=3, x 2=20.98, p=0.00)$.

\section{Opoids}

12respondents out of 440 used opoids. The prevalence was 2.7\%. 7(13.7\%) were introduced by friends, $2(8 \%)$ by relatives and 3 by other people. $3(17.7 \%)$ used opoids to read, $5(19.7 \%)$ for boldness to talk, 2(10.5\%) stimulate themselves and $2(20 \%)$ to satisfy friends. $10(27 \%)$ were sustained through friends, $1(16.7 \%)$ through their parents while $1(1.5 \%)$ through their pocket money $(\mathrm{df}=3, \mathrm{x} 2=16.95, \mathrm{p}=0.001)$. 8(12.9\%) had duration of intake as 5years and above while $4(14.3 \%)$ had taken opoid between 3-5years. One(5\%) used opoid and 1 other drug, 2(18.2\%) used opoid and 2 other drugs while $9(40.9 \%)$ used opoids and 3 other drugs. The difference was significant $(\mathrm{df}=3, \mathrm{x} 2=20.98, \mathrm{p}=0.00)$.

\section{Sniffs}

17 out 440 respondents used sniffs. The prevalence was $3.9 \%$. 8(15.7\%) were introduced by friends,3(12\%) by relatives while $6(16.7 \%)$ by other people. $7(24 \%)$ used sniffs for boldness to talk, $4(23.5 \%)$ to read, $3(15.8 \%)$ to stimulate themselves, $2(5.3 \%)$ to be alert while $1(10 \%)$ to satisfy friends. $10(27 \%)$ were sustained through their friends,5(7.2\%) through their pocket money while $2(33.3 \%)$ through their parents. The difference was significant $\mathrm{df}=3, \mathrm{x}=9.18, \mathrm{p}=$ 0.027). 9( $14.5 \%$ ) had 5years and above as duration of sniffs use, $6(21.4 \%)$ had used it between 3-5years while 2(15.4\%) had 1-3years as duration of usage. $2(3.3 \%)$ used only sniffs as psychoactive drug, 2(10\%) used sniffs and one other drug, 13(59.1\%) used 3 other drugs alongside sniffs. The difference was statistically significant ( $\mathrm{df}=3, \mathrm{x} 2=42.18, \mathrm{p}=0.00)$.

\section{Tobacco}

\section{DISCUSSION}

Thirteen point nine ( $13.9 \%$ ) prevalence use of tobacco in this study was lower than Okoza et $\mathrm{al}^{8}$ prevalence of $20 \%$ among students drawn from Ambrose Ali University, Ekpoma. The prevalence was also lower to Babatunde et al ${ }^{13}$ report of $22.6 \%$ among university students in Ekiti, Nigeria. However, higher than $10.6 \%$ prevalence report by Yisa et al ${ }^{14}$ study conducted in Ibadan, Nigeria and another $10.6 \%$ prevalence in a study conducted in Pietersburg area South Africa ${ }^{15}$. Both studies with prevalences of $10.6 \%$ were conducted among secondary school students, this might have accounted for a lower prevalence unlike those conducted among university students. About $2 / 3$ of the users had used tobacco more than 5years and above while 4 had used it between 6 months and 1year. Earlier exposure to tobacco use might also account for the difference noted. The number of drugs used alongside tobacco was significant. The more drugs taken, the possibility of tobacco being one of it is high. Tobacco is legally allowed hence the likely use by multiple drug users. 


\section{Alcohol}

The prevalence was $16.8 \%$. This is similar to a lower prevalence of alcohol reported by Yunusa et $\mathrm{al}^{11}$ in a study conducted in one of the northern university in Nigeria. However lower than prevalence of $78.4 \%$ reported by Chikere and Mayowa ${ }^{16}$ among university students in south eastern Nigeria. The prevalence was also lower than $66 \%$ reported by Okoza et al8 in a study among university students in south southern Nigeria. Achalu reported $79.1 \%$ prevalence of alcohol use among Nigeria students at universities in the United States of America ${ }^{17}$. Socio cultural variation and religious belief may account for the differences between prevalence of alcohol use among Nigeria states and other part of the world. Slightly more than half of alcohol users were introduced into its use by friends. Peer pressure is significant in aetiology of substance use and abuse.

\section{Cannabis}

The low prevalence of $7.3 \%$ is comparable to $5.8 \%$ reported by Taawasu ${ }^{18}$ and $3 \%$ reported by Yunusa at el ${ }^{11}$.but lower than the $19.2 \%$ finding of Achalu ${ }^{17}$ and $19.9 \%$ in a study among students in south city of Florianopolis ${ }^{19}$. The figure was lower than those reported from western countries. Possible explanation is the liberal use of cannabis, in fact it was reported to be legalized in Netherland.

'Boldness to talk' was the reason for their use of substance as revealed by half of the users while one fifth was to satisfy friends. This is similar to Adeyemo (2016) ${ }^{10}$ report that emphasized non medical use of cannabis.

The number of drugs used was significant as more than half of the users take cannabis and 3 other drugs. Cannabis is less expensive as compared with others like cocaine and its local availability as some are cultivated in some part of the country might have accounted for the popular use among multiple drug users.

\section{Cocaine}

$1.4 \%$ prevalence of cocaine use was similar to the finding by Adelekan et al ${ }^{20}$ who reported that the consumption of cocaine amongst youths in rural area was quite low. However lower than $16.2 \%$ reported by Okoza et al in a study among students of Ambrose Ali university , Ekpoma, Nigeria $^{8}$. Cocaine is more expensive than other psychoactive substances. This might have accounted for lower prevalence recorded in this study.

All the users were multiple drug users using cocaine and 3 or more other drugs. More than half of users depend on their friends for sustainability of the drug. The cost might again being responsible for many relying on their friends.

\section{Sedatives/Tranquillizers}

The prevalence of $4.8 \%$ was recorded among the students. Multiple drug use alongside sedatives was significant as $2 / 3$ of the users engaged in use of 4 and more drugs.

\section{Hallucinogen}

The prevalence of $0.9 \%$ hallucinogen use was found among the students. All the 4 users were engaged in multiple drugs of 4 and more. The possible explanation to this fact may be a gradual exposure to legally allowed drugs before further involvement of others like hallucinogen.

\section{Heroine, Opoid And Sniffs}

Multiple drug use of 4 and more was found to be significant. This is similar to report of polydrug use and abuse in a study conducted by Plüddermann, Flisher et al. in south Africa ${ }^{21}$. 
Tolerance to a drug and desire to have a sustained feeling might have accounted for use of multiple drugs.

\section{CONCLUSION}

The findings revealed the prevalence of the drug used, introduction to drug use and reasons for use, sustainability, duration and number of drug used among undergraduate students of Ahmadu Bello University (Samaru campus). Peer group influence in introduction and sustainability were significant with use of some of these substances. Multiple drugs used was also found to be significant with some of the so called "hard drugs" Appropriate interventions like health education, social support system, counseling, referral systems, parental supervision and enforcement of necessary laws by regulatory agencies are some of the recommendations to curb the menace in our institutions in Nigeria.

\section{References}

WHO expert committee on drug dependence twenty -six report Geneva World Health Organization. Tech Rep ser. 169 No 407

America Psychiatric Association Diagnostic and Statistical Manual of mental disorders, V th Ed. Washington, Dc 2013.

World Health Organization :International Classification of Diseases; 10 ${ }^{\text {th }}$ Revision, WHO, Geneva 2000.

Aremu S, Boman Y : Factors Influencing Drug Use Among undergraduate students in a Nigeria University.International Journal of Science and Research 2017, 6, 8 2012-2018

Office of national drug control strategy : Annual report Washington DC US government printing office 200097 42.

Annette M Nkowane and Mary A. Jansen, substance abuse in Africa, Africa Health November, 200022 (1) :15

Onya HE, Flisher AJ. Prevalence of substance use among rural high school students in Limpopo Province, South Africa. Afr J Drug Alcohol Stud. 2008;7(2).

Okoza J. Aluede 0 : drug abuse among students of Ambrose Alli University, Ekpoma, Nigeria European journal of social science 200910,1

Oshikoya, K.A. and Alli, A. (2006). Perception of Drug Abuse Amongst Nigerian Undergraduates. World Journal of Medical Sciences, 1(2), 133-139.

Adeyemo, F., Ohaeri B., Pat U.,\& Ogodo 0. ( 2006) : Prevalence of Drug Abuse Amongst University Students in Benin City, Nigeria Public Health Research, 6(2): 31-37

Yunusa, M., Obembe, A.,\& Asogwa, F. (2012) . survey of psychostimulent use among university students in Northeast Nigeria Nigeria journal of psychiatric 9,3.

Smart, G., Hughes, P., Johnstorn,D., Anumonye, A.,\& Krant, V. A methodology for student drug-use surveys(1980). Geneve: WHO Offset Publication.

Babatunde ,A., Elegbede 0., Ayodele L., Atoyebi A., Ibironge D.,\& Adeagbo A. (2012) : Cigarette Smoking Practices and Its Determinants Among University Students in Southwest, Nigeria Journal Of Asian Scientific Research 2, 6269.

Yisa IO, Lawoyin TO, Fatiregun AA, et al. Pattern of substance use among senior students of command secondary schools in Ibadan, Nigeria. Niger J Med 2009 Jan-Mar; 18(1) :98-102.

Madu SN, Matla MQ : Prevalence of Illicit drug use, cigarette smoking and alcohol drinking behaviour among sample secondary-school adolescent students around the Pietersburg area (Central Region), in the Northern Province, South Africa. Journal of adolescence 26: $12003: 2$ 121-136.

Chikere E I, Mayowa M : prevalence and perceived health effort of alcohol use among male undergraduate student in owerri south east Nigeria BMC public health 2011 11:118.

Achalu, O. E : Drug taking among Nigerian students at universities in the United state of America. Bull. Narc. issue 2008

Tawasu: Prevalence and Pattern of Substance Use among undergraduate students of University of Maiduguri, Nigeria. West Africa 2005 
Baus J, Kupek E, Pires M : assessing prevalence and risk factors associated with drug abuse among public elementary and high school students in the southern city of Florianópolis, Brazil Revista de saude publica 36:1 $20022: 40-46$.

Adelekan, M., Abiodun , A., Obayan, A., Oni, G., \& Ogunremi, O. (1992). Prevalence and Pattern Among Undergraduate in a Nigeria University. Drug Alcohol depend feb 29 (3) 255- 61.

Plüdderman, Andreas, Alan J. Flisher, Rebecca McKetin, Charles Parry, and Carl Lombard. 2010.

Methamphetamine use, aggressive behaviour, and other mental health issues among high school students in Cape Town, South Africa. Drug and Alcohol Dependence 109(1-3):14-19. 